\title{
Social criteria to develop an in use holistic urban sustainable assessment tool: UHU2SAT
}

\author{
Antonio Sánchez Cordero ${ }^{1 *}$, Marta Videras Rodríguez ${ }^{1}$, Sergio Gómez Melgar², and José Manuel Andujar Márquez² \\ ${ }^{1}$ University of Huelva, ETS Ingeniería. Programa de doctorado CYTIA. e-mail: antonio.sanchez443@alu.uhu.es \\ ${ }^{2}$ University of Huelva, ETS Ingeniería, TEP192 Control y Robótica web: http://www.controlyrobotica.com/
}

\begin{abstract}
Recently, several urban sustainability assessment tools (USAT) have appeared to reduce the human impact provided by the built environment. Few of them focus on the assessment of urban spaces like squares, streets, and parks, etc., but they don't operation and maintenance (OM) phase is not considered. It would be necessary to develop an in use holistic urban sustainable assessment tool (UHU2SAT) to specifically assess urban spaces under OM phase. This paper provides a qualitative research among 188 studies, with the aim to classify them according to the impacts they pursue: environmental (ENV), social (SOC) economic (ECO) and Others. Finally, the SOC criteria are reduced up to 21 and arranged into 4 different groups: Human comfort, Urban mobility, SOC Cohesion, and Health \& safety. These SOC criteria have been discussed and revised according to the literature review to identify the most suitable indicators for the UHU2SAT. Finally, it can be concluded that this methodology could also be useful to obtain ENV and ECO criteria to provide a holistic assessment of the sustainability.
\end{abstract}

\section{Introduction}

The built environment constitutes and important part of the human footprint over our planet. Not only for the construction processes themselves, but also because the operation and maintenance $(\mathrm{OM})$ and the recycling phases [1]. In fact, the impact of OM is more significant in developed countries [2].

According to the world's concerns, described in the United Nations' Sustainable Development Goals [3], many sustainability assessment tools have been recently appearing to reduce impacts from the built environment [4], [5]. At the beginning, these sustainability assessment tools (SAT) were focused on measuring the ENV impacts of new buildings [6]. As the time passed, they become more useful to improve buildings' sustainable design and construction through the inclusion of more factors of sustainability [7]. Then, researchers started to develop some more specific SAT adequate for different typologies, regional environment, and life cycle stages from design to operation and maintenance [8]. This provided a vast scenario with more than six hundred tools [5], [9], but focused on building' assessment.

In recent years, assessment of urban districts and cities become a reality with several SAT with specific features for that scale [10], but they are not as mature as building assessment, especially in case of urban spaces. For them, two examples of this are: CEEQUAL developed by Building Research Establishment (BRE) [11] and SITES developed by the US Green Building Council (USGBC) [12]. They both have the objective to assess urban infrastructure, landscaping and, works in public spaces, but without considering the OM phase of already in use urban spaces. Therefore, it is necessary to develop an in use holistic urban sustainable assessment tool (UHU2SAT), that can provide ground support for urban regeneration initiatives in urban spaces of developed cities. Also, it is necessary a driver for the uptake of sustainable pathways by recognizing excellence for sustainable urban spaces.

As some others declare [13], multi-criteria decisionmaking (MCDM) methodologies, and more specifically to ,multi-attribute decision-making (MADM) can be used to develop this tool [14]. The process includes the participation of different groups of experts and stakeholders that must evaluate priorities among different sustainable criteria [15], [16] [17]. Therefore, the accurate definition of the most appropriate evaluation criteria should be a fact of major importance in the creation and development of the UHU2SAT.

A truly holistic sustainability comes from the consideration of concerns like environmental (ENV) [7], social (SOC) [18], economic (ECO) [19], and others like, cultural [20], institutional [21], and technical [22]. All these impacts of sustainability must be evaluated to provide long term useful SAT. SOC impacts seems to be more difficult to evaluate according to the highest number of criteria found [23].

This research objective is to provide a critical review of 188 studies done in the recent years as well the most widely spread SAT for urban design, that establishes the foundations to define the most sustainable SOC criteria for the development of the future UHU2SAT.

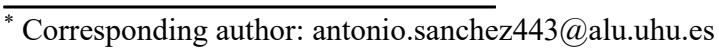




\section{Methodology}

According to the objective of this paper, the methodology proposed as follows in Figure 2.1.

\begin{tabular}{c}
$\begin{array}{c}\text { Literature } \\
\text { review }\end{array} \rightarrow \begin{array}{c}\text { SOC criteria } \\
\text { review }\end{array} \rightarrow \begin{array}{c}\text { SOC criteria for } \\
\text { UHU2SAT }\end{array}$ \\
\hline
\end{tabular}

Fig. 2.1. Three steps methodology to obtain the SOC criteria.

\subsection{Literature review}

First, a literature review has been conducted simultaneously in Scopus and Web of Science, to be considered the most relevant scientific database for this purpose [24]. Three different lists of keywords have been used to proceed with the review:

Type 1, group of words like urban sustainability assessment or indicators or criteria.

Type 2, popular acronyms like Building Research Environmental Assessment Method for Communities (BREEAM C), Leadership in Energy \& Environmental Design for Neighbourhood Development (LEED ND), Deutsche Gesellschaft für Nachhaltiges Bauen for Urban Districts (DGNB-UD), and The Comprehensive Assessment System for Built Environment Efficiency for Urban districts (CASBEEUD) [5].

- Type 3, those more specific to the assessment of urban spaces, like CEEQUAL [11], and SITES [12].

Table 2.1. Most used USAT technical manual

\begin{tabular}{|c|c|c|c|}
\hline USAT & Organization & Version & Ref. \\
\hline SITES & GBCI & V2 & {$[12]$} \\
\hline CEEQUAL & BRE & V 6 & {$[11]$} \\
\hline BREEAM C & BRE & $\begin{array}{c}\text { SD202 }- \\
0.1: 2012\end{array}$ & {$[25]$} \\
\hline LEED ND & USGBC & V 4 & {$[26]$} \\
\hline CASBEE-UD & JSBC & V 2014 & {$[27]$} \\
\hline DGNB-UD & DGNB & V 2016 & {$[22]$} \\
\hline
\end{tabular}

Additionally, these database results have later been merged into database managed by Mendeley software ${ }^{\mathrm{TM}}$.

\subsection{SOC criteria review}

Second, the results obtained from the review have been organised according to the most relevant impacts: ENV, SOC, ECO and others, but only from 2010. Also, an additional review has been carried to discard those less relevant studies. Then, several international standards, providing the specific principles for sustainability within the construction sector, have been used to classify the most relevant impact of each criterion: The UN EN 15643 series, provided by the Technical Board 350 from the European Committee of Standardization, have been used to establish the basis of SOC criteria selection. Especially, those concerning to the general framework [28], and to the SOC impacts framework [29]. The 15643-3:2012 declares that accessibility, adaptability, health and comfort, neighbourhood stress, maintenance planning, security issues, public participation should be involved in SOC sustainability.

Additionally, several USAT, with a focus on SITES and CEEQUAL have been used to obtain basis criteria for SOC assessment, see Table 2.1. It must be mentioned that several of the criteria defined in any USAT cannot be classified into a specific sustainability impact, so they are placed according to their primary objective.

\subsection{Most adequate SOC criteria for USAT}

Finally, papers with criteria focused on SOC impacts have been carefully reviewed to keep only those adequate with: OM phase, specific for urban spaces.

Table 2.2. Evaluation methodology for criteria selection

\begin{tabular}{|c|c|c|c|c|}
\hline Criteria & Objective & OM & $\begin{array}{c}\text { Urban } \\
\text { space }\end{array}$ & SOC \\
\hline Criterion & Description & $\mathrm{Y} / \mathrm{N}$ & $\mathrm{Y} / \mathrm{N}$ & $\mathrm{Y} / \mathrm{N}$ \\
\hline
\end{tabular}

\section{Results}

According to the methodology explained in Section 2, results from the literature research have been obtained and arranged into the following graphs and tables.

\subsection{Literature review}

Figure 3.1 shows the number of research items found in Scopus and Web of Science from 2010 using selected keywords established in Section 2.1.

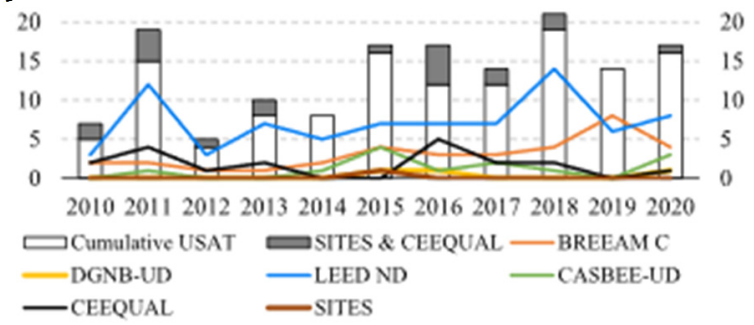

Fig. 3.1. Analysis of USATs' studies published from 2010 .

White bars include BREEAM C, CASBEE UD, DGNB UD and LEED ND, while grey bars include those specific for urban spaces, CEEQUAL and SITES. It shows no clear trend in the yearly pattern. 2011 and 2018 were the more successful years, while 2012 had less publications than any other. Specifically, colour lines describe the trend in USAT's publications per year. There, LEED ND is more cited than any other USAT with 4 to 14 publications per year, while SITES and DGNB UD very few citations. Finally, publications with CEEQUEAL and SITES are less usual than all the others. 


\subsection{SOC criteria review}

To provide a useful criteria analysis, the publications database has been reduced to consider only researches published in scientific journals, which later have been organised according the main impact of each of these ones, see Figure 3.2: ENV, SOC, ECO, or All. A growing pattern can be seen from 2010, except for the 2019, at All bars. For the rest of the bars in the figure, the trend is also increasing but with some irregularity. Considering any specific impact, the relevance ranking can be described as ENV is the first, while SOC and ECO present alternance. It is evident, that the research interests have been focused on ENV concern more than any other, but the distance is small, especially in 2016 when ENV and ECO showed the same relevance. For all years together, there are: 107 papers including ENV, 58 papers including SOC, and 68 papers including ECO, but these results may consider any combination.

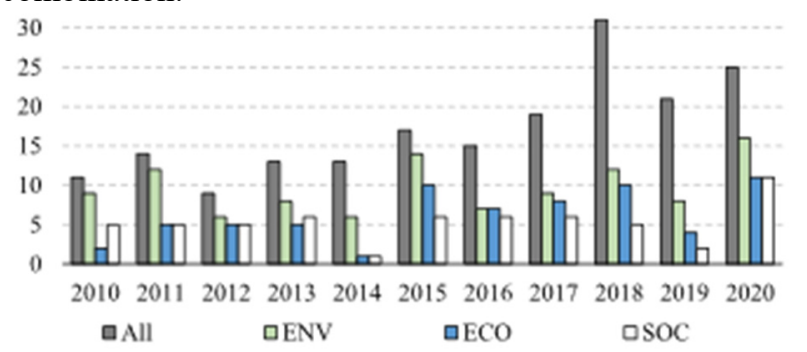

Fig. 3.2. Analysis of USATs' studies published from 2010 .

To avoid this confusion, Figure 3.3. arranges the information to provide clear evidence of criteria focused profile. 188 journal papers from Figure 3.2, have been considered. It shows which research papers include only ENV, SOC, ECO and several combinations of them.

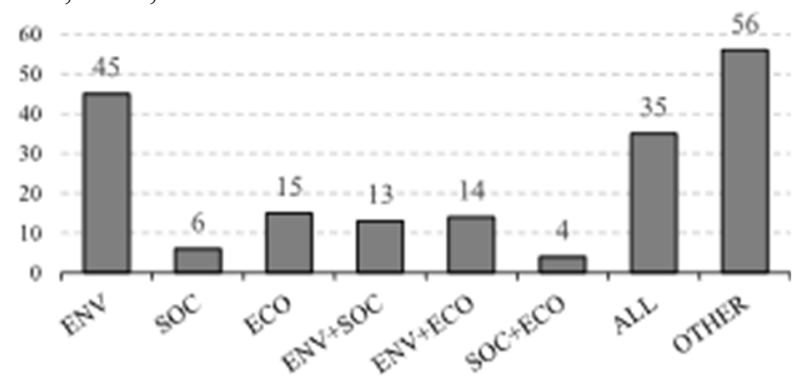

Fig. 3.3. Analysis of USATs' studies published from 2010 .

According to Figure 3.3, there are 45 studies which contain ENV criteria, while there are only 6 about SOC criteria and 15 about ECO criteria. A combination of any of these options can be seen in the following options: $\mathrm{ENV}+\mathrm{SOC}$. ENV+ECO, SOC+ECO, and ALL together. Other contains those studies that do not clearly identify in which impact they focus.

Figure 3.3 shows that ENV criteria have been widely considered already, but ECO, and specially SOC criteria have not. Therefore, it could be necessary to provide complementary research about them.

\subsection{Hierarchy Structure of the UUSSAT}

Although several of the studies from Sections 3.1 and 3.2 have worked on the development of USAT adapted to regional specific aspects of sustainability, none of these studies consider the OM phase. It would be, then necessary to provide an adequate methodology for sustainability assessment analysis based on a proper criteria selection. According to that, the combination of both criteria, mainstream commercial and independent research USATs can provide a more comprehensive review of the current state of the art. Therefore, a more precise selection of criteria, which can be made with any of the variations of the Analytic Hierarchy Process defined by Saaty [30]. The structure here can be organised in two steps: category and criteria. Finally, and according to the structural decomposition suggested, the USATs analysed here can be summarised as follows:

Table 3.1. Evaluation methodology for criteria selection

\begin{tabular}{cccc} 
USAT & Categories & Criteria & OM+ SOC \\
\hline CEEQUAL & 8 & 30 (Issues) & $5(16.66 \%)$ \\
\hline SITES & 10 (Section) & 66 (Credit) & $12(18.18 \%)$ \\
\hline BREEAM C & 5 & 40 (Issues) & $13(32.50 \%)$ \\
\hline CASBEE UD & 4 (Topic) & 35 & $9(25.71 \%)$ \\
\hline DGNB- UD & 5 (Topic) & 31 & $7(22.58 \%)$ \\
\hline LEED- ND & 3 & 49 (Credit) & $8(16.32 \%)$
\end{tabular}

CEEQUAL, now managed by BRE, is the most widely used USAT in civil engineering, infrastructure, landscaping and works in the public space [31]. Its scope includes construction or refurbishments, from strategy and design to construction, but it doesn't include OM phase. It is structured in categories, issues, and assessment criteria which are evaluated through sets of indicators [11]. It includes 30 different criteria. According to the methodology showed in Table 2.2, 15 of these criteria could be adequate for the OM phase of an urban space assessment. Surprisingly, only 5 of them can consider SOC impact as the most important, which is the $16.66 \%$ of all criteria. See Table 3.1.

SITES is a rating system for sustainable land design and development managed by the Green Business Certification Inc (GBCI). It can apply to outside projects like: Open spaces (garden, parks, etc.), streetscapes and plazas, retail and office' outdoor areas, neighbourhood yards, public and private campuses; And also, any kind of infrastructure [12]. Its main goal is to enhance regenerative strategies for urban areas. As CEEQUAL SITES has been developed to assess construction or refurbishments for any of the urban places mentioned above, but it neither includes the OM phase. It is structured in sections, and credits which are evaluated through sets of indicators [12]. It includes 66 different credits, but they include 16 prerequisites that must be achieved prior to any further consideration. According to the methodology showed in Table 2.2, 33 of these criteria could be adequate for the OM phase of an urban space assessment, but finally, only 12 of them can considered SOC impact as the most 
important one, which is the $18.18 \%$ of all criteria. See Table 3.1.

According to their scope CEEQUAL, and SITES, are supposed to provide more adequate criteria for small scale urban spaces than BREEAM C, CASBEE-UD, DGNBUD, and LEED-ND. However, they all have been analysed to obtain a more comprehensive result. Their hierarchy structure of these USATs can be seen in the Table 3.2, where the relevance of the $\mathrm{OM}+\mathrm{SOC}$ criteria is: $32.50 \%$ in BREEAM C, $25.71 \%$ in CASBEE-UD, $22.58 \%$ in DGNB-UD, and $16.32 \%$ in LEED-ND.

In Figure 3.4. the graph bar shows only those criteria than can be adequate for urban spaces at the OM phase but divided into SOC or Other criteria. There, BREEAM C provides 13, and SITES provides 12, while the others provide from 9 to $5 \mathrm{SOC}$ criteria. On the contrary,
SITES provides 21, and LEED-ND provides 19, while the others provide from 15 to 10 criteria for any impact different than SOC. Some of these SOC criteria are very similar so they have been reduced to Table 3.2.

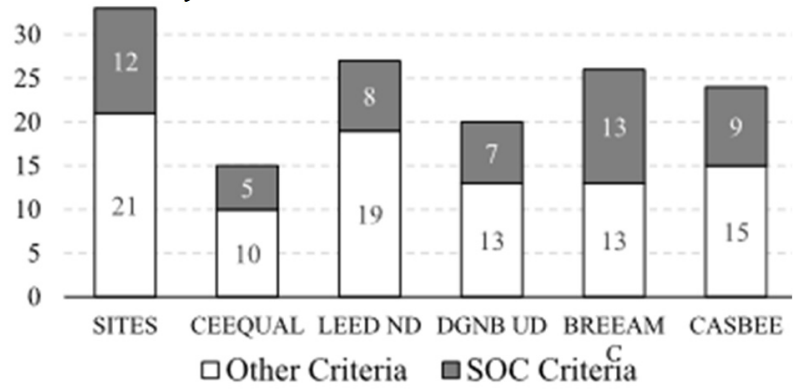

Fig. 3.4. OM urban space criteria comparison

Table 3.2. SOC criteria for the UHU2SAT

\begin{tabular}{|c|c|c|c|}
\hline Group & Criteria & Aim & Reference \\
\hline \multirow{5}{*}{$\begin{array}{l}\text { Human } \\
\text { comfort }\end{array}$} & $\begin{array}{l}\text { Micro-climate: Hygrothermal comfort } \\
\text { on site }\end{array}$ & $\begin{array}{c}\text { Promote a pleasant all year round comfort which meets the highest number of } \\
\text { user's requirements }\end{array}$ & {$[25][26][22]$} \\
\hline & $\begin{array}{l}\text { Heat island effect: Hygrothermal } \\
\text { comfort off site }\end{array}$ & $\begin{array}{l}\text { Minimize the effects of urban heat island through the use of vegetation and } \\
\text { reflective materials on surfaces }\end{array}$ & {$[12][26]$} \\
\hline & Lighting design & $\begin{array}{l}\text { Provide a comfortable visual environment on-site that allows different age users to } \\
\text { perform multiple outdoor tasks }\end{array}$ & {$[22]$} \\
\hline & Lighting pollution control & $\begin{array}{l}\text { Minimise, mitigate, and manage the negative effects of night-time lighting } \\
\text { pollution for neighbours and astronomers }\end{array}$ & {$[11][25][26]$} \\
\hline & Noise intrusion control & $\begin{array}{c}\text { Minimise, mitigate, and manage the negative effects of noise pollution on different } \\
\text { age users }\end{array}$ & {$[11][25][22]$} \\
\hline \multirow{5}{*}{$\begin{array}{l}\text { Urban } \\
\text { mobility }\end{array}$} & Connected pedestrian networks & $\begin{array}{l}\text { Provide safe pedestrian ways not only on site, but also connected with walkways } \\
\text { routes to the site surrounding facilities }\end{array}$ & {$[11][25][27]$} \\
\hline & Emissions free vehicles network & $\begin{array}{l}\text { Ensure facilities for bicycles and similar emissions free transports to enhance } \\
\text { human health }\end{array}$ & {$[25][26]$} \\
\hline & Public transport network & Ensure public local transport networks on-site surroundings & $\begin{array}{l}{[11][25][26]} \\
{[27]}\end{array}$ \\
\hline & Multi-modal transport networks & $\begin{array}{l}\text { Improve human health and reduce pollution on site with networks that connects } \\
\text { pedestrian, emissions free vehicles, and public lines }\end{array}$ & {$[11][12][25]$} \\
\hline & Sustainable parking & $\begin{array}{l}\text { Ensure the parking facilities have the precise size to provide service and it is not } \\
\text { affecting any other urban mobility criterion }\end{array}$ & {$[25]$} \\
\hline \multirow{5}{*}{$\begin{array}{c}\text { SOC } \\
\text { Cohesion }\end{array}$} & Inclusive design & $\begin{array}{c}\text { Guarantee the entire built environment accessible and usable for all, regardless of } \\
\text { their physical status }\end{array}$ & {$[11][25][22]$} \\
\hline & Commercial facilities nearby & $\begin{array}{l}\text { Ensure accessible supplies nearby, that enhances usability of the urban space and } \\
\text { integration into a wider area }\end{array}$ & $\begin{array}{l}{[25][26]} \\
{[27][22]}\end{array}$ \\
\hline & $\begin{array}{l}\text { Green infrastructure and mental } \\
\text { restoration }\end{array}$ & $\begin{array}{c}\text { Guarantee inclusive high-quality green infrastructure space for all to provide visual } \\
\text { and physical connections between users and nature }\end{array}$ & $\begin{array}{l}{[12][25][26]} \\
{[27]}\end{array}$ \\
\hline & Recreation facilities & Provide physical activity and SOC networking facilities & {$[12][26]$} \\
\hline & Crime prevention & $\begin{array}{l}\text { Ensure on-site 24-h safety conditions, through facilities like: night security lighting } \\
\text { and security cameras among others }\end{array}$ & {$[27]$} \\
\hline \multirow{6}{*}{$\begin{array}{c}\text { Health \& } \\
\text { safety }\end{array}$} & Hazardous materials & Assure no hazardous material is of claddings and coatings & {$[12]$} \\
\hline & Plants management control & $\begin{array}{l}\text { Guarantee human and plants health by promoting gardening practices with nearly } \\
\text { zero use of pesticides and fertilizers }\end{array}$ & {$[12]$} \\
\hline & Tobacco free space & Assure tobacco is ban within the urban space and its surroundings & {$[12]$} \\
\hline & Maintenance protocol management & $\begin{array}{l}\text { Minimization of air quality and noise disturbance through the proper use of } \\
\text { maintenance management plan. }\end{array}$ & {$[11][12][22]$} \\
\hline & Water disposal facilities & Provide free clean water disposal for all users & \\
\hline & Evacuation plan & Evaluation of a disaster prevention plan and evacuation strategies & {$[27]$} \\
\hline
\end{tabular}




\section{Discussion}

From the information contained in Figure 3.2 can be seen how ENV, SOC and ECO criteria have been considered by the authors during the last 10 years. ENV appears in more studies than SOC and ECO, but the distance between them is not excessive. On the contrary, when data for all years are considered together, studies considering ENV criteria are much more than those considering SOC or ECO, even with any combinations between them. This is showing a lack of research interest when SOC criteria must be specifically developed. The interest of this study on developing SOC criteria for a new UHU2SAT has been justified.

Results shown in Table 3.1, provide the hierarchy structure of the most relevant USAT. According to the table, SITES and BREEAM C, contain the highest number of SOC criteria available for OM, with 12 and 13 each one. On the contrary, CEEQUAL has only 5 of them, which is inconsistent with the initial suggestion. If BREEAM-C, and CEEQUAL are both USAT from BRE, but with CEEQUAL developed to work at a smaller scale, how is it possible to have less SOC criteria adequate for the development of the UHU2SAT. First, the hierarchy structure of the USAT does not correspond with the same hierarchy. Second, BREEAM C includes more criteria than CEEQUAL [25] [11], so then the differences expressed in percentage are less important, 32.50 vs $16.60 \%$. Third, the BREEAM-C, as CASBEE-UD, DGNB-UD and LEED-ND give more importance to SOC and ECO criteria than any other SAT [32]. Finally, BREEAM-C contains a higher number of SOC criteria related to urban mobility than CEEQUAL, but many of them have a very similar aim, so they can be merged into a few ones. Additionally, the scales are different [33].

Figure 3.4 shows those criteria obtained thorough the methodology explained in Table 2.2, where the criteria are divided into two groups: SOC versus Others. There, CEEQUAL seems less representative than SITES and any other USATs for the selection of useful criteria development of the UHU2SAT, see Figure 3.4.

The problem for many of these criteria is that they are not suitable for mall scale urban spaces as Medved, and $\mathrm{Xu}$ et al, suggest [19] [34]. Other authors suggest to assess sustainability, according to the size of the geographic scenario[35], or to use the proper criteria sets according to the scale to balance the SOC and the ECO impact [36]. Finally, others like Ameen et al proposed [17], a reduction of criteria from most relevant USATs, which has several similarities with the methodology sections 2.1 , to 2.3 .

Final results from Table 3.3. can be discussed according to be structure suggested into 4 groups that cover the most common aspects of SOC sustainability.

\subsection{Human comfort criteria}

This group includes 5 different criteria. Microclimate and Heat island effect aim to provide comfort to humans based on the hygrothermal conditions: temperature and relative humidity, which also are affected by solar radiation and wind. On site comfort can be measured through real-time monitoring devices and manage with adaptive comfort theories as other authors suggested [37], [38]. The percentage of the site where the comfort dissatisfaction is less than a defined limit can be used to guarantee minimum comfort conditions, according to a site's climate [25] [26] [22]. On the contrary, the heat island effect doesn't have a direct impact on site, but it contributes to the district's warm up [12] [26]. It can be reduced through the proper use of reflective surfaces.

To enhance artificial lighting design on-site, best lighting design standards must be applied. It will guarantee a proper luminance level without glaring and appropriate for the tasks carried on-site [22]. On the contrary, these lighting devices should neither provide upwards lighting pollution, nor neighbours visual disturbance around the site. [11] [25] [26]. Both, criteria could be measured on site through proper electronic devices.

Finally, Acoustic comfort must be assessed through both, noise maps from reliable institutions that considers latest updates around-site and proper measuring devices to validate data from the acoustic map [11] [25] [22].

\subsection{Urban mobility}

Connected pedestrian [11] [25] [27]and Emissions-free vehicle network [25] [26] aim to assess the adequacy of the site to provide safe ways for alternative transport. The assessment would require the use of mobility maps of both on-site and the surrounding area.

The Public transport network can improve urban mobility through the presence of transport's lines to connect with the city, which is something considered in most of the USATs analysed in this study [11] [25] [26] [27] [17]. Additionally, these public transport lines could be connected to bicycle and/or pedestrian networks converting into multimodal networks [11] [12] [25], which introduce a higher benefit for user's mobility.

Finally, reduced parking facilities should be introduced, but only for institutional purposes, like police, firemen, or ambulance as well as handicapped private users [25].

\subsection{Social Cohesion}

Inclusive design aims the urban space to provide an integrative design to assure people of all ages, gender, and physical condition can use it [11] [25] [22]. It can be assessed through design plans and visual inspection on site according to best practices inclusive standards [39].

Commercial facilities around site enhance the usability, as well as provide a positive effect in other SOC and ECO criteria [25] [26] [27] [22]. It can be assessed with a district commerce on-site inspection, where variety is more important than repetition [25].

Green infrastructure is important to provide environments with visual and physical connections with 
nature [12] [25] [26] [27], where biophilic districts have shown a great potential on this concern. It can be assessed through ratios between green-soft versus grey-hard spaces [40], within the urban space or its surroundings. It can be used to comply with Recreation facilities criteria to provide more appealing urban spaces. Paved areas can be considered as recreation facilities if they allow physical activity and network facilities. Green infrastructure and Recreation facilities can both be assessed through as built plans and on-site verifications.

Crime prevention, which could be included in the Health and Safety group, aims to assure the site has been provided with security facilities: adequate lighting and cameras as well as vigilance plans [27]. It is, therefore, connected with lighting design criteria.

\subsection{Health \& Safety}

Hazardous materials, Plants management control and Tobacco free space are willing to mitigate long term effects from the exposition to harmful chemicals on-site [12]. Hazardous materials can be assessed through on-sites report about cladding materials. Ecological gardening practices must follow ecological agriculture and can be assessed trough reviews of the gardening management plan [41]. Finally, Tobacco ban can be assessed through proper signage on-site inspection.

Water disposal facilities aim to enhance heath habits by providing free fresh water [42]. It should consider water quality, accessibility, proper sanitation plan, and infection control like Covid-19 and Legionella [43].

Maintenance protocol management aims to avoid environmental and human disturbance from noise and air pollution [11] [12] [22]. It can be properly assessed through the review of the maintenance plan, including gardening, cleaning, and occasional reparations.

Evacuation plan assesses the existence of a proper security plan in case of emergencies [27], with potential on-site risks and evacuation routes with safe meeting point.

In summary, several USATs have been used as sources to provide the most influencing SOC criteria to develop the UHU2SAT, where: Human comfort is more influenced by BREEAM-C, LEED-ND, and DGNB-UD, Urban mobility is more affected by BREEAM-C, SOC Cohesion is affected in the same way by BREEAM-C, LEED-ND, and CASBEE-UD., finally, Health \& Safety group is widely affected by SITES.

\section{Conclusion}

The current state of the art about USAT has been proved insufficient to assess the holistic sustainability of urban spaces in use. This paper suggests new sets of SOC criteria classified into 4 groups, specifically useful to the develop a new in use holistic urban sustainable assessment tool UHU2SAT. Future research focused on ENV and ECO criteria should be necessary prior to the final development of the UHU2SAT.

\section{References}

1. L. Pérez-Lombard, J. Ortiz, and C. Pout, "A review on buildings energy consumption information," Energy Build., vol. 40, no. 3, pp. 394-398, 2008.

2. I. Martínez-Zarzoso and A. Maruotti, "The impact of urbanization on $\mathrm{CO} 2$ emissions: Evidence from developing countries," Ecol. Econ., vol. 70, no. 7, pp. 1344-1353, 2011.

3. UNECE, "SDG Priorities," 2019. [Online]. Available: https://www.unece.org/sustainable-development/sdgpriorities.html. [Accessed: 22-Oct-2019].

4. U. Berardi, "Clarifying the new interpretations of the concept of sustainable building," Sustain. Cities Soc., vol. 8, pp. 72-78, 2013.

5. A. S. Cordero, S. G. Melgar, and J. M. A. Márquez, "Green building rating systems and the new framework level(s): A critical review of sustainability certification within Europe," Energies, vol. 13, no. 1, pp. 1-25, 2019.

6. D. T. Doan, A. A. Ghaffarianhoseini, N. Naismith, T. Zhang, A. A. Ghaffarianhoseini, and J. Tookey, "A critical comparison of green building rating systems," Build. Environ., vol. 123, pp. 243-260, Oct. 2017.

7. B. R. Keeble, "The Brundtland Report: 'Our Common Future," Med. War, vol. 4, no. 1, pp. 17-25, 1988.

8. T. P. Obrecht, R. Kunic, S. Jordan, and M. Dovjak, "Comparison of Health and Well-Being Aspects in Building CertificationSchemes," SUSTAINABILITY, vol. 11, no. 9, May 2019.

9. S. Vierra, Green Building Standards and certification systems. Steven Winter Associates, 2014.

10. A. L. Chao, A. C. Gallego, V. Lopez-Chao, and A. Alvarellos, "Indicators framework for sustainable urban design," Atmosphere (Basel)., vol. 11, no. 11, pp. 1-18, 2020.

11. Building Research Establishment, "CEEQUAL Version 6 Technical Manual | International Projects SD6053:0.0.”p. 197, 2019.

12. Sustinable Sites Initiative and Others, "SITES V2. Rating System for sustainable Land Design and Development," Sustainable Site Initiative: Austin, $T X$, USA. 2014

13. S. Mahmoud, T. Zayed, and M. Fahmy, "Development of sustainability assessment tool for existing buildings," Sustain. Cities Soc., vol. 44, pp. 99-119, Jan. 2019.

14. V. Penadés-Plà, T. García-Segura, J. V. Martí, and V. Yepes, "A review of multi-criteria decision-making methods applied to the sustainable bridge design," Sustainability (Switzerland), vol. 8, no. 12. MDPI AG, 2016.

15. [15] development of sustainable assessment method for Saudi Arabia built environment: weighting system," Sustain. Sci., vol. 10, no. 1, pp. 167-178, 2015.

16. H. Kang, Y. Lee, and S. Kim, "Sustainable building 
assessment tool for project decision makers and its development process," Environ. Impact Assess. Rev., vol. 58, pp. 34-47, 2016.

17. R. F. M. Ameen, M. Mourshed, and H. Li, "A critical review of environmental assessment tools for sustainable urban design," Environ. Impact Assess. Rev., vol. 55, pp. 110-125, Nov. 2015.

18. K. Gompf, M. Traverso, and J. Hetterich, "Towards social life cycle assessment of mobility services: systematic literature review and the way forward," Int. J. Life Cycle Assess., vol. 25, no. 10, pp. 1883-1909, Oct. 2020.

19. P. Medved, "A contribution to the structural model of autonomous sustainable neighbourhoods: New socioeconomical basis for sustainable urban planning," $J$. Clean. Prod., vol. 120, pp. 21-30, 2016.

20. L. Cities, U., \& Governments, "Culture: fourth pillar of sustainable development.," United Cities Local Gov. Policy Statement., 2010.

21. M. Holden, "Sustainability indicator systems within urban governance: Usability analysis of sustainability indicator systems as boundary objects," Ecol. Indic., vol. 32, pp. 89-96, Sep. 2013.

22. Deutsche Gesellschaft für Nachhaltiges Bauen, "Overview of all criteria for quarters," 2020. [Online]. Available: https://www.dgnbsystem.de/de/quartiere/kriterien/. [Accessed: 24Nov-2020].

23. A. Merino-Saum, P. Halla, V. Superti, A. Boesch, and C. R. Binder, "Indicators for urban sustainability: Key lessons from a systematic analysis of 67 measurement initiatives," Ecol. Indic., vol. 119, 2020.

24. A. Aghaei Chadegani et al., "A comparison between two main academic literature collections: Web of science and scopus databases," Asian Soc. Sci., vol. 9, no. 5, pp. 18-26, 2013.

25. Buiding Research Environmentl Assesment Method, "BREEAM Communities. Technical Manual SD202 0.1:2012." p. 175, 2012.

26. US Green Building Council, "LEED v 4 for Neigborhood development.” 2018.

27. JSCB (Japan Sustainable Building Consortium) and Japan Sustainable Building Consortium, "CASBEE Certification System," 2019. [Online]. Available: http://www.ibec.or.jp/CASBEE/english/certification E.htm. [Accessed: 12-Sep-2019].

28. European Committee for Standardization, EN 15643 1: 2010. Sustainability of construction works. Sustainability assessment of buildings. Part 1: General framework. 2010.

29. European Committee for Standardization, EN 156433: 2012. Sustainability of construction works. Assessment of buildings. Part 3: Framewoork for the assessment of social performance. 2012.

30. M. Medineckiene, E. K. Zavadskas, F. Björk, and Z. Turskis, "Multi-criteria decision-making system for sustainable building assessment/certification," Arch. Civ. Mech. Eng., vol. 15, no. 1, pp. 11-18, Jan. 2015.
31. I. Čadež and S. Hofmann, "Sustainability assessment scheme for transport infrastructure projects [Anforderungen an die Bewertung der Nachhaltigkeit von Straß enbauwerken]," Bautechnik, vol. 90, no. 10, pp. 609-613, 2013.

32. $\mathrm{P}$. Wu, Y. Song, X. Hu, and X. Wang, “A preliminary investigation of the transition from green building to green community: Insights from LEED ND," Sustain., vol. 10, no. 6, 2018.

33. D. Dizdaroglu and T. Yigitcanlar, "A parcel-scale assessment tool to measure sustainability through urban ecosystem components: The MUSIX model," Ecol. Indic., vol. 41, pp. 115-130, Jun. 2014.

34. Y. Xu, R. Keivani, and A. J. Cao, "Urban sustainability indicators re-visited: lessons from property-led urban development in China," Impact Assess. Proj. Apprais., vol. 36, no. 4, pp. 308-322, 2018.

35. W. W. Kropp and J. K. Lein, "Scenario Analysis for Urban Sustainability Assessment: A Spatial Multicriteria Decision-Analysis Approach," Environ. Pract., vol. 15, no. 2, pp. 133-146, Jun. 2013.

36. C. Li and J. Li, "Assessing urban sustainability using a multi-scale, theme-based indicator framework: A case study of the Yangtze River Delta region, China," Sustain., vol. 9, no. 11, 2017.

37. J. F. Nicol and M. A. Humphreys, "Adaptive thermal comfort and sustainable thermal standards for buildings," in Energy and Buildings, 2002, vol. 34, no. 6.

38. C.F.R.E.S., "RUROS home page. Rediscovering the Urban Realm and Open Spaces." [Online]. Available: http://alpha.cres.gr/ruros/. [Accessed: 02-Dec-2020].

39. K. C. Wu and L. Y. Song, "A case for inclusive design: Analyzing the needs of those who frequent Taiwan's urban parks," Appl. Ergon., vol. 58, pp. 254-264, 2017.

40. T. Beatley and P. Newman, "Biophilic cities are sustainable, resilient cities," Sustain., vol. 5, no. 8, pp. 3328-3345, 2013.

41. H. Eckert, G. Breitschuh, and D. R. Sauerbeck, "Criteria and standards for sustainable agriculture," $J$. Plant Nutr. Soil Sci., vol. 163, no. 4, pp. 337-351, 2000.

42. S. Naji and J. Gwilliam, "Neighborhood sustainability assessment tools and water system adaptation: A framework to analyse the adaptive capacity in the physical-social context," Int. J. Sustain. Dev. Plan., vol. 11, no. 6, pp. 907-916, 2016.

43. International WELL Building Institute (IWBI), "The WELL Community Standard.” p. 148, 2017. 